\title{
LENGTH AND TORSION OF THE LOWER LIMB
}

W. STRECKER, P. KEPPLER, F. GEBHARD, L. KINZL

From the University of Ulm, Germany

Corrective osteotomies are often planned and performed on the basis of normal anatomical proportions. We have evaluated the length and torsion of the segments of the lower limb in normal individuals, to analyse the differences between left and right sides, and to provide tolerance figures for both length and torsion.

We used CT on 355 adult patients and measured length and torsion by the UIm method. We excluded all patients with evidence of trauma, infection, tumour or any congenital disorder.

The mean length of 511 femora was $46.3 \pm 6.4 \mathrm{~cm}$ $( \pm 2 \mathrm{SD})$ and of 513 tibiae $36.9 \pm 5.6 \mathrm{~cm}$; the mean total length of 378 lower limbs was $83.2 \pm 11.4 \mathrm{~cm}$ with a tibiofemoral ratio of 1 to $1.26 \pm 0.1$. The 99th percentile level for length difference in $\mathbf{1 7 8}$ paired femora was $1.2 \mathrm{~cm}$, in 171 paired tibiae $1.0 \mathrm{~cm}$ and in 60 paired lower limbs $1.4 \mathrm{~cm}$.

In 505 femora the mean internal torsion was $24.1 \pm$ $17.4^{\circ}$, and in 504 tibiae the mean external torsion was $34.9 \pm 15.9^{\circ}$. For 352 lower limbs the mean external torsion was $9.8 \pm 11.4^{\circ}$. The mean torsion angle of right and left femora in individuals did not differ significantly, but mean tibial torsion showed a significant difference between right $\left(36.46^{\circ}\right.$ of external torsion) and left sides $\left(33.07^{\circ}\right.$ of external torsion). For the whole legs torsion on the left was $7.5 \pm 18.2^{\circ}$ and $11.8 \pm 18.8^{\circ}$, respectively $(p<0.001)$. There was a trend to greater internal torsion in femora in association with an increased external torsion in tibiae, but we found no correlation. The 99th percentile value for the difference in 172 paired femora was $1^{\circ}$; in 176 pairs of tibiae it was $14.3^{\circ}$ and for 60 paired lower limbs $15.6^{\circ}$.

These results will help to plan corrective osteotomies in the lower limbs, and we have re-evaluated the mathematical limits of differences in length and torsion.

J Bone Joint Surg [Br] 1997;79-B:1019-23.

Received 19 February 1997; Accepted after revision 30 May 1997

W. Strecker, MD

P. Keppler, MD

F. Gebhard, MD

L. Kinzl, MD, Professor

Department of Traumatology Hand and Reconstructive Surgery, University of Ulm, Steinhovelstrasse 9, D-89070 Ulm, Germany.

Correspondence should be sent to Dr W. Strecker.

(C)1997 British Editorial Society of Bone and Joint Surgery

0301-620X/97/67701 \$2.00
Anatomical studies ${ }^{1}$ of the lower limb have established the regularity of the mechanical axis as proved by clinical and radiological studies. ${ }^{2}$ The ideal mechanical axis is defined by a line between the centre of the femoral head, the knee and the centre of the ankle. Any deviation from this optimal axis is considered to be pathological. ${ }^{3}$

The geometry of the leg is difficult to define, partly because of the variable terms used to describe rotation. Torsion is the rotation within a bone segment, and varies according to the method of measurement. Rotation is used to describe the range of movement of joints between the segments.

We could find no clear evaluation or definition of the normal values for length and torsion in adults, and therefore aimed to measure and define them.

\section{MATERIALS AND METHODS}

From 1991 to 1995 we used CT on 355 patients to determine the length and torsion of the femur and tibia in healthy volunteers and the normal limbs of patients with unilateral fractures of the femur or tibia. All the limbs were asymptomatic in subjects with no history of trauma, tumour or any congenital disorder. There were 231 men and 124 women. All the women were over 16 years of age (mean 35.8; range 16 to 73 ) and the men were over 18 years of age (mean 32.3 years; range 18 to 78 ). We have used CT measurement of length and torsion since 1989. Since the radiation exposure by the Ulm method is less than that for corresponding radiological techniques no ethical approval was necessary.

Informed consent of all patients was obtained as for standard radiographic examinations.

We used a GE 9800 Quick CT (General Electric, Milwaukee, Oregon) with highlight detector. The limbs were fixed by a foot-rest mounted on the table, to provide a reproducible position. A scout view allowed the use of standard planes; angles were measured by a standard software program. The technical details and the radiation doses have been reported by Waidelich, Strecker and Schneider. ${ }^{4}$ We use standard CT to show the centre of femoral head, the centre of the greater trochanter, the dorsal tangent of the femoral condyles and the tibial head and a line across the ankle. Pfeifer et al $^{5}$ have reported the reproducibility of the method. Internal torsion is shown by a minus sign (-) and external torsion by a plus sign (+).

Statistical analysis. We used the Winstat V 3.1 program 


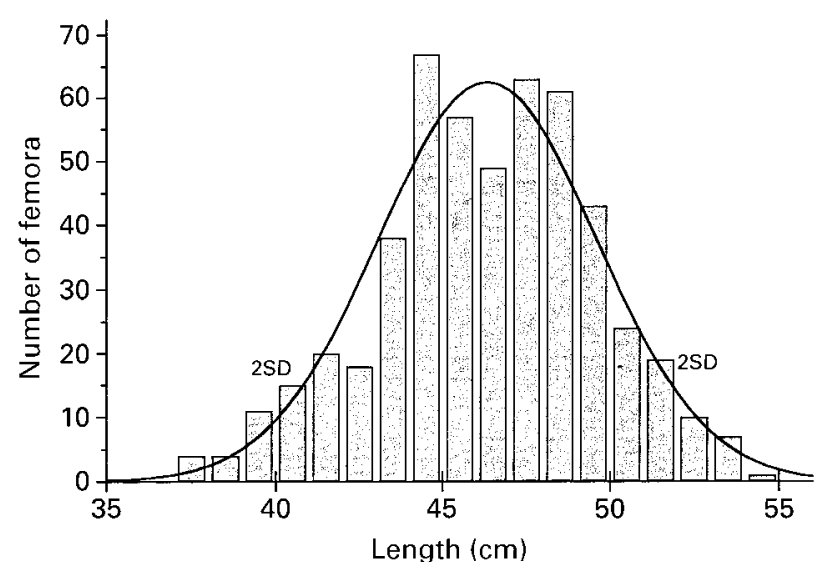

Fig. 1a

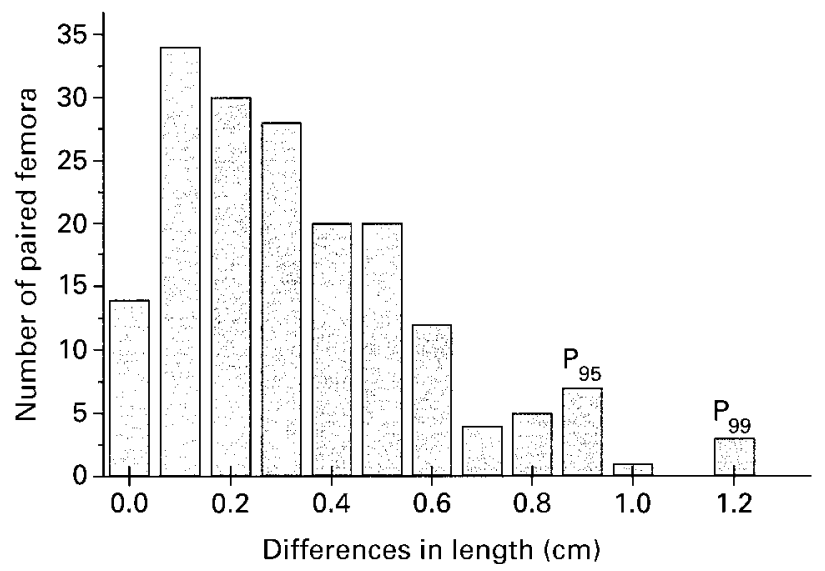

Fig. $1 \mathrm{~b}$

Figure 1a - Distribution of the length of 511 intact femora. Figure $1 \mathrm{~b}-$ Intraindividual differences in the length of 178 paired femora. The 95 th and 99 th percentiles are indicated as $\mathrm{P}_{95}$ and $\mathrm{P}_{99}\left(\right.$ median $\left.=0.3 ; \mathrm{P}_{95} / \mathrm{P}_{99}=0.9 / 1.2\right)$.

(Kalmia Company Inc, Cambridge, Massachusetts). In case of normal statistical distribution data are given as mean \pm $2 \mathrm{sD}$. Other results were expressed as medians with 95th and 99th percentiles. Differences between groups were analysed using a two-tailed $t$-test. Statistical significance was set at a $99 \%$ confidence level $(\mathrm{p}<0.01)$.

\section{RESULTS}

\section{Length}

Femur. The mean length of 511 intact adult femora (246 left, 265 right) was $46.31 \pm 6.37 \mathrm{~cm}$ (37.2 to 54.1; Fig. 1a). The means of $46.28 \pm 6.34 \mathrm{~cm}$ for the left side and $46.36 \pm$ $6.39 \mathrm{~cm}$ for the right side were not significantly different $(\mathrm{p}=0.71)$.

On 178 healthy paired femora, we evaluated individual differences between left and right sides (Fig. 1b), but in the absence of a normal statistical distribution, report the data as medians and percentiles. The difference between medians was $0.3 \mathrm{~cm}$. The between-side difference of length was $0.9 \mathrm{~cm}$ at the 95th percentile level and $1.2 \mathrm{~cm}$ at the 99th percentile level.

Tibia. The 513 intact tibiae had a mean length of $36.98 \pm$ $5.62 \mathrm{~cm}$ (29.2 to 43.7$)$ with a normal distribution (Fig. 2a), and there was no significant difference between sides $(\mathrm{p}=0.98)$.

In 171 healthy paired tibiae the difference between sides was similar to that for the femora (Fig. 2b). The median of the differences was $0.3 \mathrm{~cm}$, with a difference of $0.8 \mathrm{~cm}$ at the 95th percentile level and $1.0 \mathrm{~cm}$ at the 99th percentile level.

Lower limb. The mean length of 378 healthy legs was $83.19 \pm 11.37 \mathrm{~cm}(67.9$ to 96.7$)$ with a normal distribution (Fig. 3a) and no significant difference between sides $(\mathrm{p}=0.49)$.

In 60 pairs of normal legs, the median difference in length was $0.6 \mathrm{~cm}$ and the 95th percentile level was $1.1 \mathrm{~cm}$ (Fig. 3b).

We calculated the ratio of femoral to tibial length using 205 right and 173 left legs. This was $1.26 \pm 0.1 \mathrm{~cm}$ (Fig.
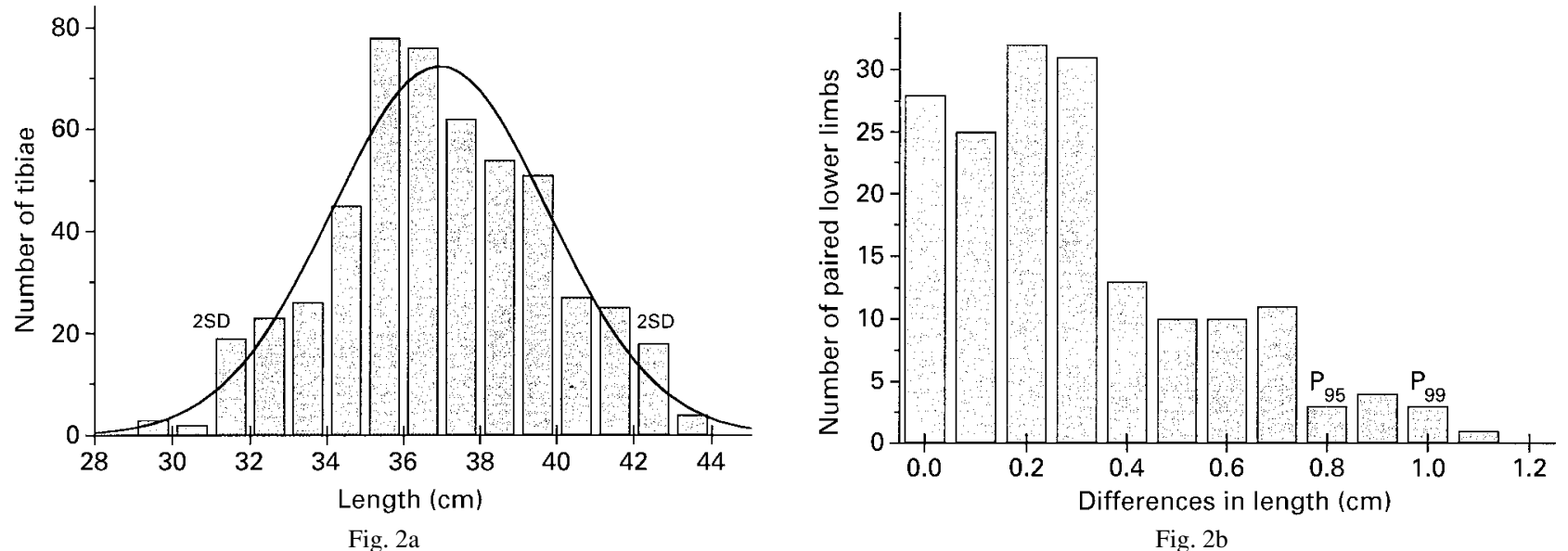

Fig. $2 b$

Figure $2 \mathrm{a}-$ Distribution of the length of 513 intact tibiae. Figure $2 \mathrm{~b}-$ Intraindividual differences in the length of 171 paired tibiae $\left(\right.$ median $=0.3, \mathrm{P}_{95} /$ $\left.\mathrm{P}_{99}=0.8 / 1.0\right)$. 


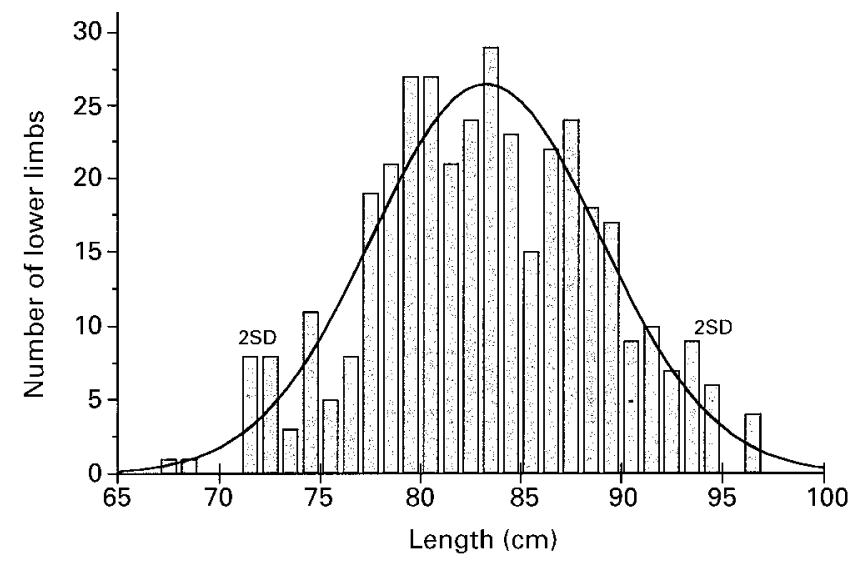

Fig. 3a

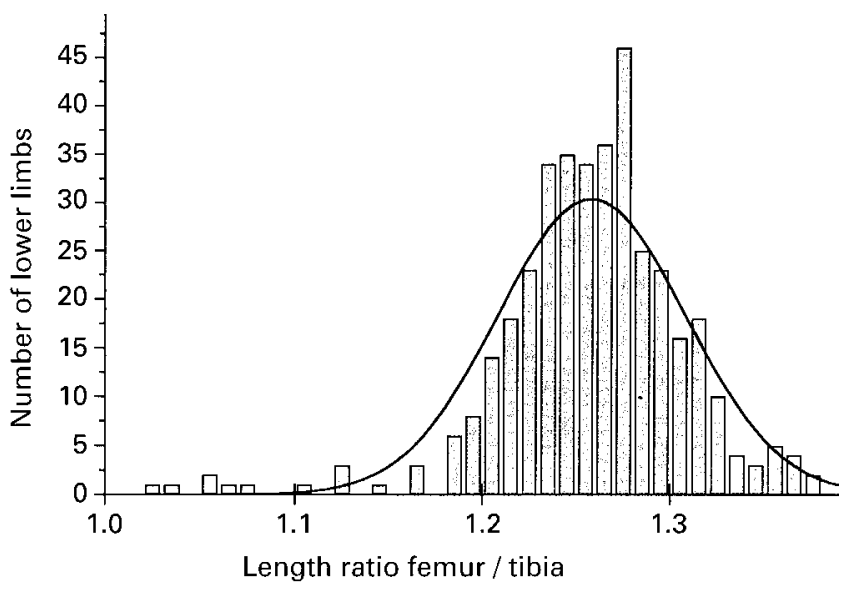

Fig. 3c

$3 \mathrm{c})$; there was a trend for greater length on the right side but no significant difference at the level which we set $(\mathrm{p}=0.40)$.

\section{Torsion}

Femur. The torsion of 505 intact femora showed a normal distribution (Fig. 4a). The mean value for 263 rightsided femora was $-23.77 \pm 18.27^{\circ}$ and for 242 left-sided

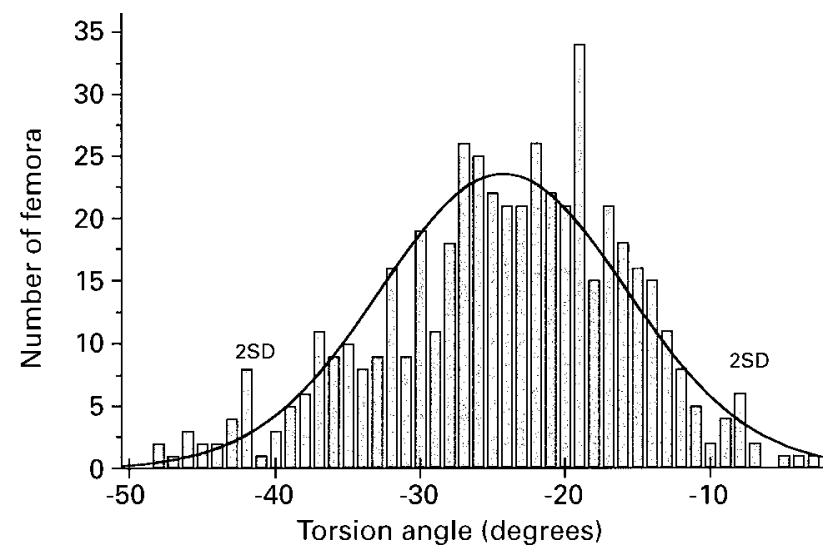

Fig. $4 \mathrm{a}$

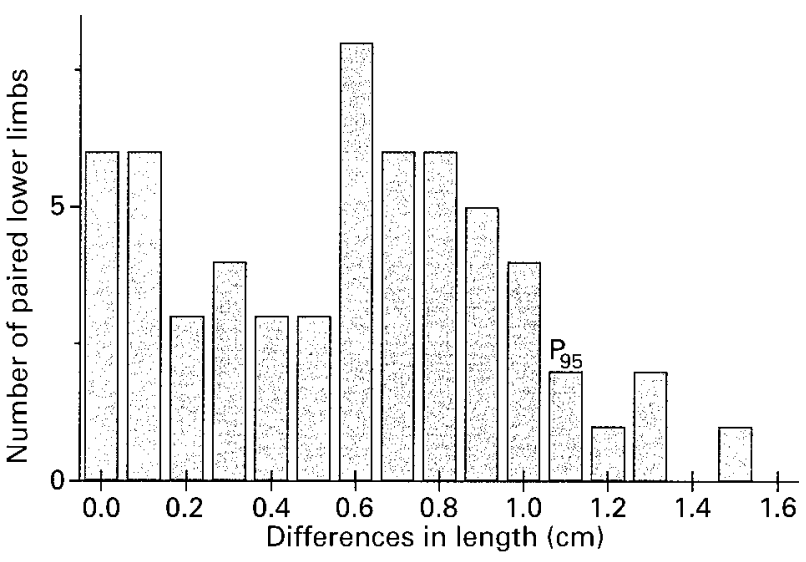

Fig. $3 b$

Figure $3 a-$ Distribution of the length of 378 paired lower limbs. Figure $3 b$ - Intraindividual differences in length of 60 paired lower limbs (median $=0.6 ; P_{95}=1.1$ ). Figure $3 c-$ Distribution of femoral-to-tibial length ratio in 378 legs.

femora $-24.46 \pm 16.30^{\circ}$. There was no significant difference between the sides $(\mathrm{p}=0.37)$. The overall range was $-1^{\circ}$ to $-48^{\circ}$.

In 172 healthy paired femora (Fig. 4b), the median of the differences between sides was $4^{\circ}$. The difference in torsion was $11^{\circ}$ at the 95 th percentile level and $13^{\circ}$ at the 99th percentile level.

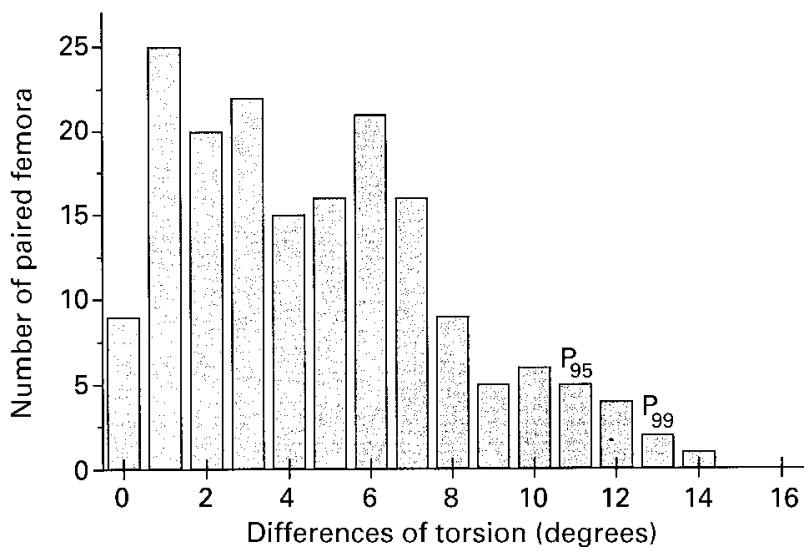

Fig. 4b

Figure $4 \mathrm{a}-$ Distribution of torsion angles in 505 femora. Figure $4 \mathrm{~b}-$ Intraindividual differences of torsion in 172 paired femora $\left(\right.$ median $=4$; $\mathrm{P}_{95} /$ $\left.\mathrm{P}_{99}=11 / 13\right)$.

VOL. 79-B, No. 6, NOVEMBER 1997 


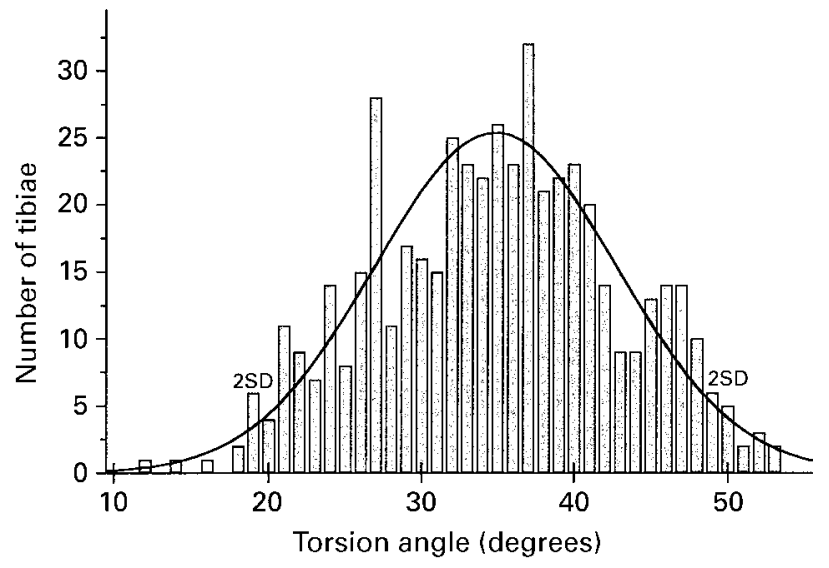

Fig. 5a

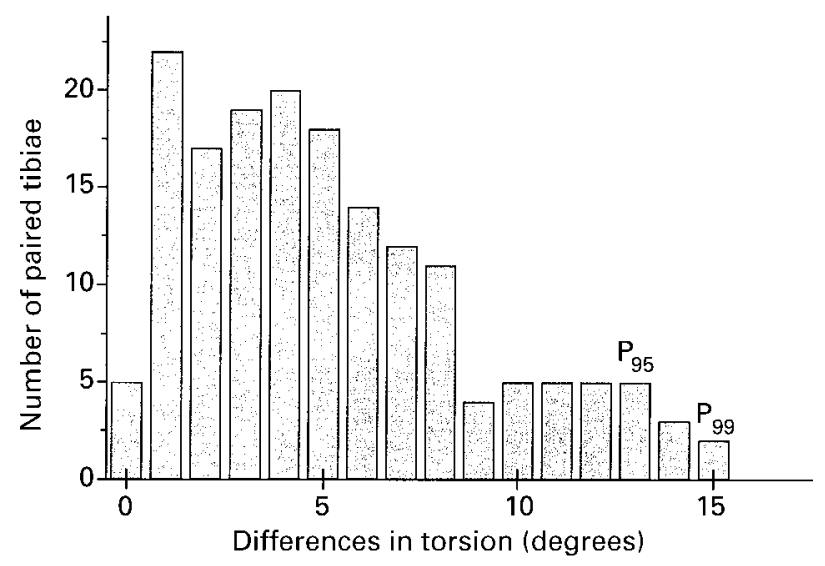

Fig. $5 \mathrm{~b}$

Figure 5a - Distribution of torsion angles in 504 tibiae. Figure $5 \mathrm{~b}-$ Intraindividual differences in torsion of 176 paired tibiae $\left(\mathrm{median}=4.9 ; \mathrm{P}_{95} / \mathrm{P}_{99}=13 /\right.$ 14.3)

Tibia. The torsion of 504 intact tibiae gave a mean value $+34.85 \pm 15.85^{\circ}$ and showed a nearly normal distribution (Fig. 5a), with a mean torsion of $+36.46^{\circ}$ for the right tibiae and $+33.07^{\circ}$ for the left. This difference was significant $(\mathrm{p}<0.001)$. The range was from $+19^{\circ}$ to $+50.9^{\circ}$ with a min/ max distribution from $+12^{\circ}$ to $+53^{\circ}$.

In 176 healthy paired tibiae (Fig. 5b) the difference between sides did not show a normal distribution. The median of the differences was $4.9^{\circ}$ with $13^{\circ}$ at the 95 th percentile level and $14.3^{\circ}$ at the 99th percentile level.

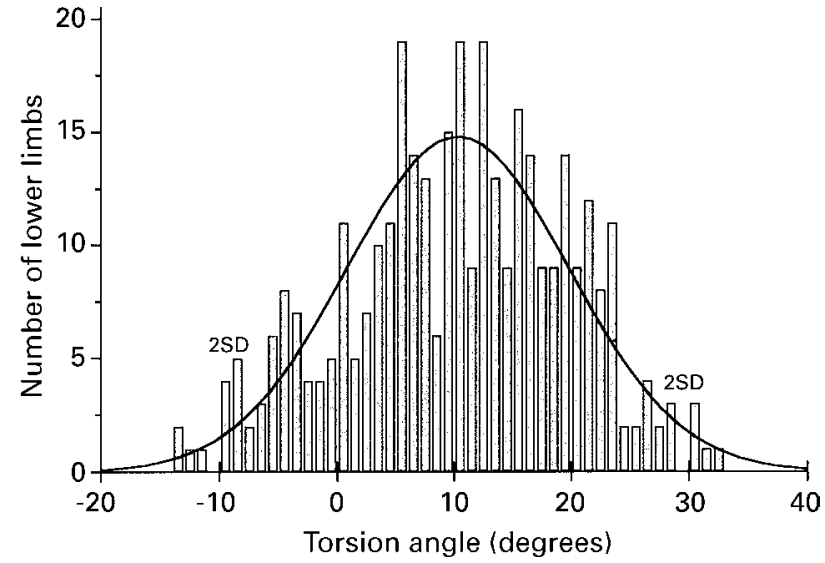

Fig. 6a

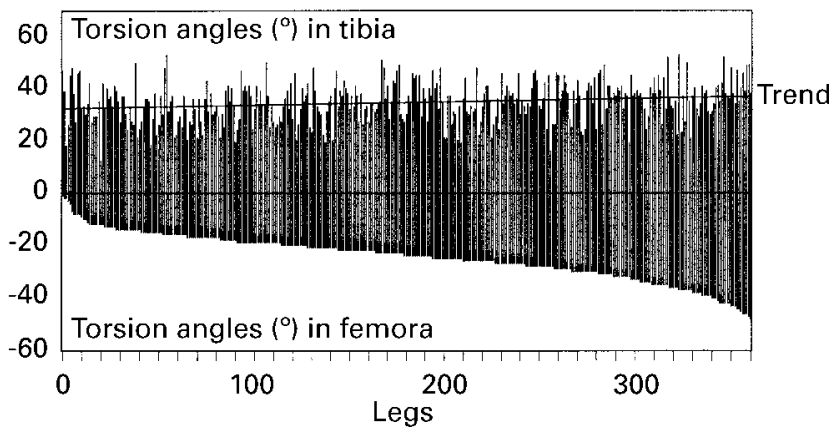

Fig. 6c
Lower limb. We measured the torsion angle of 192 healthy right and 160 left legs (mean $9.82 \pm 18.97^{\circ}$ ) with a normal distribution (Fig. 6a). On the right side the mean angle was $+11.79 \pm 18.77^{\circ}$ and on the left $+7.46 \pm 18.10^{\circ}$ which was a significant difference $(\mathrm{p}<0.001)$. The torsion limits ranged from $-1.55^{\circ}$ to $+21.39^{\circ}$ with a $\mathrm{min} / \mathrm{max}$ distribution from $-14^{\circ}$ to $+32^{\circ}$. Evaluation of the side-to-side differences in torsion was made for 48 healthy legs. The distribution was not normal (Fig. 6b); the median difference in torsion was $5^{\circ}$ and the 95 th percentile difference was $13.6^{\circ}$

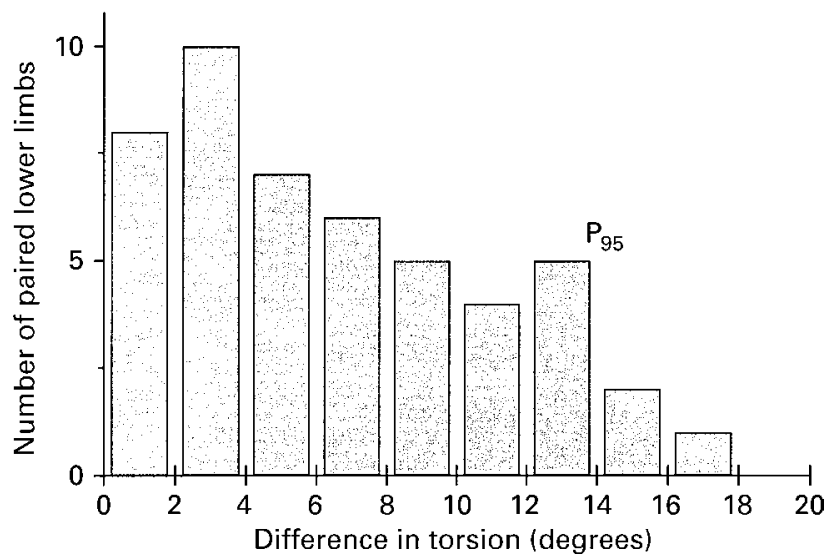

Fig. 6b

Figure $6 \mathrm{a}$ - Distribution of torsion angles in 352 legs. Figure $6 \mathrm{~b}-$ Intraindividual differences in torsion of 48 paired legs (median $=5$; $\mathrm{P}_{95}=13.6$ ). Figure $6 \mathrm{c}-$ Femoral-to-tibial ratio of intraindividual torsion angles in 362 legs. 
The ratio of femoral to tibial torsion (Fig. 6c) showed no correlation $(\mathrm{p}=0.21)$.

\section{DISCUSSION}

We measured length and torsion using the 'Ulm method' as described by Waidelich et al. ${ }^{4}$ The mean values of the length for all right and all left femora were nearly identical, and the mean values for tibial length did not differ significantly. Our results for femoral-to-tibial ratio confirm those of Mikulicz ${ }^{1}$ who reported a proportion of 5:4 in 60 lower limbs. This is commonly used as the basis for correction of length in lower limbs.

In individual patients, the relative deviation between sides is important, although the variance from the mean value of torsion is of interest only in patients with bilateral injuries or congenital disorders. ${ }^{6}$ The inward torsion of the femur does not correlate with the ipsilateral external torsion of the tibia, confirming our earlier results on larger numbers of patients. 4

The mean torsion of left and right femora differed only slightly, but we found a significant difference in tibial torsion. Right tibiae showed an increased mean external torsion of $3.39^{\circ}$ compared with left tibiae; this agrees with most published data; ${ }^{7-11}$ only two studies found no difference between sides. ${ }^{12,13}$ There were different mean values of leg torsion for right $\left(11.8^{\circ}\right)$ and left $\left(7.5^{\circ}\right)$ sides, but no correlation between right and left sides has been reported.

In line with Braten et $\mathrm{al}^{8}$ our results show a side-to-side individual tolerance of torsion with a maximum of $15^{\circ}$. The same holds true for the femur, the tibia and the whole leg. ${ }^{14,15}$ Moulton and Upadhyay ${ }^{16}$ reported a maximum of $6^{\circ}$ in normal subjects, but they studied only 21 patients.

Both general and local conditions must be considered with the full history of any malalignment before treatment decisions are made. In congenital disorders there is some functional accommodation with time, but this does not occur in adults with post-traumatic abnormalities. ${ }^{17}$ In our opinion, the indication for lengthening osteotomy for congenital shortening of the femur or tibia is a difference greater than $3 \mathrm{~cm}$. For post-traumatic shortening of the lower limb in adults, our indication for lengthening the limb is a difference in leg length of 1.5 to $2.0 \mathrm{~cm}$. Concern- ing torsional deformities of the lower limb the indication of corrective osteotomy depends basically not only on absolute or relative deviations of the torsion angles but on the inability of full rotation of the adjacent joints according to the neutral zero method.

No benefits in any form have been received or will be received from a commercial party related directly or indirectly to the subject of this article.

\section{REFERENCES}

1. Mikulicz J. Ueber individuelle Formdifferenzen am Femur und an der Tibia des Menschen. Archiv f AuPh Anat Abthig 1878:351-404.

2. Lang J, Wachsmuth W. Bein und Statik. Praktische anatomie. Erster Band, Vierter Teil. 2nd ed. Berlin: Springer-Verlag, 1972.

3. Tscherne H, Gotzen L. Posttraumatische Fehlstellungen. In: Zenker $\mathrm{R}$, Deucher F, Schink W (Hrsg). Chirurgie der Gegenwart, Bd IV a. Urban \& Schwarzenberg, München, 1978:1-76.

4. Waidelich HA, Strecker W, Schneider E. Computed tomographic torsion-angle and length-measurement of the lower extremity: the methods, normal values and radiation load. Fortschr Röngenstr 1992; 157:245-51.

5. Pfeifer T, Strecker W, Wohrle A et al. Grenzen der Torsionswinkelmessung und Längenbestimmung mit der Computer tomographie. In Strecker W Keppler P, Kinzl L (Hsrg). Posttraumatische Beindeformitaten - Analyse und Korrektur. Berlin: Springer, 1997:30-8.

6. Cooke TDV, Price N, Fisher B, Hedden D. The inwardly pointing knee: an unrecognized problem of external rotational malalignment. Clin Orthop 1990;260:56-60.

7. Strecker W, Franzreb M, Pfeifer T, et al. Computerised tomography measurement of torsion angle of the lower extremities. Unfallchirurg 1994;97:609-13.

8. Bråten M, Terjesen T, Rossvoll I. Femoral anteversion in normal adults: ultrasound measurements in 50 men and 50 women. Acta Orthop Scand 1992;63:29-32.

9. Clementz BG. Assessment of tibial torsion and rotational deformity with a new fluoroscopic technique. Clin Orthop 1989;245:199-209.

10. Clementz BG, Magnusson A. Assessment of tibial torsion employing fluoroscopy, computed tomography and the cryosectioning technique. Acta Radiol 1989;30:75-80.

11. Dupuis PV. La torsion tibiale. Desoer et Masson, Paris, 1951.

12. Le Damany PGM. La torsion du tibia normale, pathologique, expérimentale. J Anat Physiol 1909;45:598-615.

13. Jakob RP, Haertel M, Stüssi M. Tibial torsion calculated by computerised tomography and compared to other methods of measurement. $J$ Bone Joint Surg [Br] 1980;62-B:238-42.

14. Brouwer KJ, Molenaar JC, van Linge B. Rotational deformities after femoral shaft fractures in childhood: a retrospective study 27-32 years after the accident. Acta Orthop Scand 1981;52:81-9.

15. Butler-Manuel PA, Guy RL, Heatley FW. Measurement of tibial torsion: a new technique applicable to ultrasound and computed tomography. Br J Radiol 1992;65:119-25.

16. Moulton A, Upadhyay SS. A direct method of measuring femoral anteversion using ultrasound. J Bone Joint Surg [Br] 1982;64-B: 469-72.

17. Pfeil J, Grill F, Graf R. Extremitätenverlängerung, Deformitätenkorrektur, Pseudarthrosenbehandlung. Berlin, etc: Springer, 1996. 